\title{
Peripheral ganglia in healthy rats as target structures for the evaluation of PSMA imaging agents
}

Heike Endepols ${ }^{1,2,3 \dagger}$, Agnieszka Morgenroth ${ }^{4 \dagger}$, Boris D. Zlatopolskiy ${ }^{1,3 \dagger}{ }^{+}$, Philipp Krapf ${ }^{1,3}$, Johannes Zischler ${ }^{1,3}$, Raphael Richarz', Sergio Muñoz Vásquez ${ }^{2}$, Bernd Neumaier ${ }^{1,3^{*}+}$ (i) and Felix M. Mottaghy $y^{4,5^{*+}}$

\begin{abstract}
Background: The recent implementation of PET with prostate specific membrane antigen (PSMA)-specific radiotracers into the clinical practice has resulted in the significant improvement of accuracy in the detection of prostate carcinoma (PCa). PSMA-expression in ganglia has been regarded as an important pitfall in prostate carcinoma-PET diagnostics but has not found any practical use for diagnosis or therapy.

Methods: We explored this phenomenon and demonstrated the applicability of peripheral ganglia in healthy rats as surrogates for small PSMA positive lesions for the preclinical evaluation of diagnostic PCa PET probes. Healthy rats were measured with PET/CT using the tracers $\left[{ }^{18} \mathrm{~F}\right] \mathrm{DCFPyL},\left[\mathrm{Al}{ }^{18} \mathrm{~F}\right] \mathrm{PSMA}-11$ and $\left[{ }^{68} \mathrm{Ga}\right] \mathrm{PSMA}-11$. Sections of ganglia were stained with an anti-PSMA antibody. $\left[{ }^{18} \mathrm{~F}\right] \mathrm{DCFPyL}$ uptake in ganglia was compared to that in LNCaP tumor xenografts in mice.

Results: Whereas $\left[{ }^{18} \mathrm{~F}\right] \mathrm{DCFPyL}$ and $\left[{ }^{68} \mathrm{Ga}\right] \mathrm{PSMA}-11$ were stable in vivo and accumulated in peripheral ganglia, $\left.[\mathrm{A}]^{18} \mathrm{~F}\right] \mathrm{PSMA}-11$ suffered from fast in vivo deflourination resulting in high bone uptake. Ganglionic PSMA expression was confirmed by immunohistochemistry. $\left[{ }^{18} \mathrm{~F}\right] \mathrm{DCFPyL}$ uptake and signal-to-noise ratio in the superior cervical ganglion was not significantly different from LNCaP xenografts.

Conclusions: Our results demonstrated the non-inferiority of the novel model compared to conventionally used tumor xenografts in immune compromised rodents with regard to reproducibility and stability of the PSMA signal. Furthermore, the model involves less expense and efforts while it is permanently available and avoids tumorgrowth associated animal morbidity and distress. To the best of our knowledge, this is the first tumor-free model suitable for the in vivo evaluation of tumor imaging agents.
\end{abstract}

Keywords: Prostate carcinoma, Radiofluorination, Positron emission tomography, Imaging, Preclinical model

\section{Background}

Prostate-specific membrane antigen (PSMA) is a membrane bound type II zinc metallopeptidase which hydrolyzes $C$-terminal glutamate residues of small peptides in the extracellular space. The natural substrates of PSMA

\footnotetext{
* Correspondence: b.neumaier@fz-juelich.de; fmottaghy@ukaachen.de Heike Endepols, Agnieszka Morgenroth and Boris D. Zlatopolskiy are equally contributing first authors.

Bernd Neumaier and Felix M. Mottaghy are equally contributing last authors. ${ }^{1}$ Institute of Radiochemistry and Experimental Molecular Imaging, University of Cologne, Faculty of Medicine and University Hospital Cologne, 50937 Cologne, Germany

${ }^{4}$ Department of Nuclear Medicine, University Hospital, RWTH Aachen, Pauwelsstraße 30, Aachen 52074, Germany

Full list of author information is available at the end of the article
}

are the neurotransmitter $N$-acetylaspartylglutamate (NAAG) [1] and polyglutamate folate (pteroylpolyglutamate) [2]. PSMA expression is strongly upregulated in prostate carcinoma $(\mathrm{PCa})$ and correlates with tumor malignancy (reviewed in [3]) making PSMA an attractive target for $\mathrm{PCa}$ diagnosis and treatment. In tumors, PSMA is supposed to be involved in folate uptake [4] as well as in laminin proteolysis which favor angiogenesis and re-endothelialization $[5,6]$. The released glutamate binds to tumor cell metabotropic glutamate receptors stimulating tumor growth via phosphoinositide 3-kinaserelated signaling pathways [7]. In recent years, PET or SPECT tracers for PSMA imaging have become

(c) The Author(s). 2019 Open Access This article is distributed under the terms of the Creative Commons Attribution 4.0 International License (http://creativecommons.org/licenses/by/4.0/), which permits unrestricted use, distribution, and reproduction in any medium, provided you give appropriate credit to the original author(s) and the source, provide a link to the Creative Commons license, and indicate if changes were made. The Creative Commons Public Domain Dedication waiver (http://creativecommons.org/publicdomain/zero/1.0/) applies to the data made available in this article, unless otherwise stated. 
important tools for PCa diagnostics [8-10]. In addition, radioligands labeled with therapeutic radionuclides like ${ }^{177} \mathrm{Lu}$ and ${ }^{225} \mathrm{Ac}$ have been successfully used for PSMAtargeted radiotherapy in prostate cancer [11, 12]. A suitable probe for molecular imaging or targeted radiotherapy should combine high specificity and long retention in target tissue with a rapid washout from non-target organs [13]. Usually, preclinical validation of novel radioligands for tumor imaging comprises in vitro studies of tracer uptake in target positive and negative cell lines as well as in vivo evaluation in appropriate animal models. The most common approaches employ tumor xenografts in immunodeficient animals [14]. While these models are generally well suited for assessment of target specificity and tumor binding kinetics, there are also some drawbacks. Since the blood vessels and stroma cells in human tumor xenografts are of murine origin, their growth is often irregular, and necrotic or cystic areas can be present already in small $(8-10 \mathrm{~mm})$ tumors. Poor blood supply can affect the penetration and distribution of imaging agents in tumors. Microbial or viral contamination of tumor cells could significantly affect not only survival and response of the immune deficient murine host but also properties of tumor tissues like immunogenicity, growth rate and metastatic potential [15]. Therefore, immunocompromised animals need to be housed and handled under specific pathogen-free conditions, which is laborious and expensive. For an initial in vivo screening of newly developed PSMA ligands, a facile alternative to xenograft models may be beneficial.

PSMA-specific uptake of PET tracers in human cervical, coeliac and sacral ganglia is well documented in the literature [16-18]. Similar to humans, rat ganglionic PSMA is expressed by satellite glial cells [19], which envelop the neuronal cell bodies of peripheral ganglia. Electron microscopic studies have shown that PSMA is mainly localized in the cell membrane of satellite cells [20]. PSMA/ $\beta$-actin expression ratio is 1.5 for rat dorsal root ganglia [19], while it amounts to 6.8 for $\mathrm{LNCaP}$ prostate carcinoma cells [21]. PSMA in rat dorsal root ganglia shows an enzymatic activity of $9.9 \pm 1.7 \mathrm{pmol}$ $\mathrm{NAAG} / \mathrm{min} / \mathrm{mg}$ [20], while in the superior cervical ganglion PSMA activity $(26.5 \pm 0.2 \mathrm{pmol} \mathrm{NAAG} / \mathrm{min} / \mathrm{mg})$ [20] is virtually equal to that of LNCaP cells $(29.0 \pm 2.6$ pmol NAAG/min/mg) [22], which are broadly used for PCa xenograft models.

Having a size of only $1-2 \mathrm{~mm}$, rat ganglia have the potential to mimic metastases in a very early stage. Rat PSMA comprises 752 amino acids (vs. 750 in humans), and is about $91 \%$ homologous to human PSMA. Importantly, all amino acid residues of the active site are essentially the same as those in the human homologue. The only exception is $\mathrm{Ser}^{548}$ in the rat instead of Gly ${ }^{548}$ in the human protein [23]. Not surprisingly, rat and human PSMA show comparable kinetic parameters for hydrolysis of NAAG and similar inhibition profiles [23]. We have already used peripheral ganglia of healthy rats for the preclinical screening of novel PSMA ligands [24]. This study resulted in discovery of a PSMA PET probe with favorable imaging properties which is already used in clinic $[25,26]$. However, a thorough characterization of the model is still lacking. In this study we show that the ganglion model affords reproducible PET images with PSMA-specific PET tracers. PSMA-specificity of tracer binding is confirmed by immunohistochemistry and autoradiography. We examinated the applicability of this model using two widely used PSMA specific PET probes: $\left[{ }^{68} \mathrm{Ga}\right]$ PSMA-11 [27] and $\left[{ }^{18} \mathrm{~F}\right]$ DCFPyL [28]. As an example of a PSMA-ligand with low in vivo stability we used PSMA-11 labeled with $\mathrm{Al}^{18} \mathrm{~F}$ [29-31]. Finally, we compared $\left[{ }^{18} \mathrm{~F}\right] \mathrm{DCFPyL}$ PET-scans obtained in healthy rats with those from LNCaP tumor-bearing SCID mice.

\section{Methods}

The aim of this study was to demonstrate the applicability of peripheral ganglia in healthy rats as surrogates for small PSMA positive lesions for the preclinical evaluation of PCa PET probes. Healthy rats were measured with small animal PET/CT using the tracers $\left[{ }^{18} \mathrm{~F}\right] \mathrm{DCFPyL}$, $\left[\mathrm{Al}^{18} \mathrm{~F}\right]$ PSMA-11 and $\left[{ }^{68} \mathrm{Ga}\right]$ PSMA-11. Anti-PSMA immunohistochemistry was used to confirm ganglionic PSMA expression. Rat superior cervical ganglia and mouse LNCaP tumor xenografts were compared with respect to $\left[{ }^{18} \mathrm{~F}\right] \mathrm{DCFPyL}$ uptake and signal-to-noise ratio.

\section{Production of $\left[{ }^{18} \mathrm{~F}\right]$ fluoride}

$\left[{ }^{18} \mathrm{~F}\right]$ Fluoride was produced by the ${ }^{18} \mathrm{O}(\mathrm{p}, \mathrm{n}){ }^{18} \mathrm{~F}$ reaction by bombardment of $98 \%$ enriched $\left[{ }^{18} \mathrm{O}\right]$ water with 16.5 $\mathrm{MeV}$ protons at the MC16 cyclotron of the Max Planck Institute of Neurological Research in Cologne (Scanditronix, Uppsala, Sweden).

\section{Synthesis of tracers}

$\left[{ }^{18} \mathrm{~F}\right] \mathrm{DCFPyL}$ was synthesized according to the modified procedure of Neumaier et al. (WO2016030329A1) using the "minimalist" protocol [32] and $\left[\mathrm{Al}^{18} \mathrm{~F}\right]$ PSMA-11 according to Boschi et al. [30]. [ $\left.{ }^{68} \mathrm{Ga}\right] \mathrm{PSMA}-11$ was produced according to the method reported previously [33, 34].

Synthesis of 2,3,5,6-tetrafluorophenyl 6- $\left[{ }^{18} \mathrm{~F}\right]$ fluoropyridine-3-carboxylate $\left(\left[{ }^{18} \mathrm{~F}\right] \mathrm{FPy}-\mathrm{TFP}\right)$ : Aqueous $\left[{ }^{18} \mathrm{~F}\right]$ fluoride $(0.05-50 \mathrm{GBq})$ was loaded onto a Sep-Pak Accell Plus QMA carbonate plus light cartridge (Waters $\mathrm{GmbH}$, Eschborn, Germany) preconditioned with $\mathrm{H}_{2} \mathrm{O}$ $(1 \mathrm{~mL})$. The resin was washed with anhydrous $\mathrm{EtOH}(3$ $\mathrm{mL})$ and $\left[{ }^{18} \mathrm{~F}\right]$ fluoride was eluted into the reaction vessel with a solution of $\left[{ }^{18} \mathrm{~F}\right]$ FPy-TFP-precursor, $N, N, N$ - 
trimethyl-5-[(2,3,5,6-tetrafluorophenoxy)-carbonyl]pyridine-2-aminium trifluoromethanesulfonate $(10 \mathrm{mg}$, $21 \mu \mathrm{mol})$, in anhydrous EtOH $(200 \mu \mathrm{L})$. Thereafter, the resin was washed into the reaction vessel with anhydrous $\mathrm{MeCN} / t \mathrm{BuOH}$ 1:4 $(2 \mathrm{~mL})$. The mixture was stirred at $45^{\circ} \mathrm{C}$ for $15 \mathrm{~min}$. After cooling to ambient temperature, the reaction mixture was diluted with water $(20 \mathrm{~mL})$ and loaded onto a polymer RP cartridge (the cartridge was preconditioned with $2 \mathrm{~mL}$ EtOH followed by $30 \mathrm{~mL} \mathrm{H}_{2} \mathrm{O}$ ). The cartridge was washed with water $\left(10 \mathrm{~mL}\right.$ ) and $\left[{ }^{18} \mathrm{~F}\right]$ FPy-TFP (up to $25 \mathrm{GBq}$, radiochemical yield (RCY): $40-75 \%$ decay-corrected to EOB) was eluted with EtOH $(500 \mu \mathrm{L})$. The radiochemical and chemical purities after SPE purification were $>98 \%$ determined by HPLC [eluent: $50 \% \mathrm{MeCN}$; flow rate: 1.5 $\mathrm{mL} / \mathrm{min}$; column: Chromolith ${ }^{\circ}$ SpeedROD RP-18e column (Merck, Darmstadt Germany), $50 \times 4.6 \mathrm{~mm}$; retention time: $2.0 \mathrm{~min}$ ].

Synthesis of $\left[{ }^{18} \mathrm{~F}\right] \mathrm{DCFPyL}$ : To a solution of $\{[(S)-5$ amino-1-carboxypentyl]carbamoyl\}-(S)-glutamic acid (Lys-CO-Glu, $2.5 \mathrm{mg}, 7.8 \mathrm{mmol}$ ) in $0.19 \mathrm{M} \mathrm{Et}_{4} \mathrm{NHCO}_{3}$ in anhydrous EtOH $(160 \mu \mathrm{L})\left[{ }^{18} \mathrm{~F}\right] \mathrm{FPy}$-TFP $(1-10 \mathrm{GBq})$ in $\mathrm{EtOH}(500 \mathrm{~mL})$ was added and the mixture was allowed to stir at $45^{\circ} \mathrm{C}$ for $3-5 \mathrm{~min}$. The mixture was quenched with $\mathrm{H}_{2} \mathrm{O}(2 \mathrm{~mL})$ and purified by preparative HPLC (eluent: saline $(0.9 \% \mathrm{NaCl})$ with $10 \% \mathrm{EtOH})$; flow rate: 8 $\mathrm{mL} / \mathrm{min}$, column: Synergi $4 \mu \mathrm{m}$ Hydro-RP $80 \AA 100 \times$ $21.2 \mathrm{~mm}$; retention time: $7.0 \mathrm{~min}$ ). Finally, the purified product was passed through a sterile $0.2 \mu \mathrm{m}$ filter. $\left[{ }^{18} \mathrm{~F}\right] \mathrm{DCFPyL}$ was prepared in $75-90 \%$ RCY. The molar activity amounted to $80-138 \mathrm{GBq} / \mu \mathrm{mol}(n=35)$. Analytical HPLC conditions were as follows: eluent: $10 \% \mathrm{EtOH}$ in aq. $\mathrm{H}_{3} \mathrm{PO}_{4}(\mathrm{pH} 2)$ for $5 \mathrm{~min}$, then $50 \% \mathrm{EtOH}$ in aq. $\mathrm{H}_{3} \mathrm{PO}_{4}(\mathrm{pH}$ 2) for $2 \mathrm{~min}$; flow rate: $1.5 \mathrm{~mL} / \mathrm{min}$; column: Chromolith $^{\circ}$ SpeedROD RP-18e column (Merck, Darmstadt, Germany), $50 \times 4.6 \mathrm{~mm}$; retention times: $\left[{ }^{18} \mathrm{~F}\right]$ DCFPyL $3.0 \mathrm{~min}$ and $\left[{ }^{18} \mathrm{~F}\right]$ FPy-Tfp $5.8 \mathrm{~min}$.

Synthesis of $\left[\mathrm{Al}^{18} \mathrm{~F}\right] \mathrm{PSMA}-11$ : Aqueous $\left[{ }^{18} \mathrm{~F}\right]$ fluoride (0.05-50 GBq) was loaded onto a Sep-Pak Accell Plus QMA carbonate plus light cartridge (Waters $\mathrm{GmbH}$, Eschborn, Germany) preconditioned with $0.5 \mathrm{~m} \mathrm{NaOAc}$ (pH 4.5; $10 \mathrm{~mL})$ followed by $\mathrm{H}_{2} \mathrm{O}(10 \mathrm{~mL})$. The cartridge was washed with $\mathrm{H}_{2} \mathrm{O}(5 \mathrm{~mL})$ and $\left[{ }^{18} \mathrm{~F}\right]$ fluoride was eluted with $0.5 \mathrm{M} \mathrm{NaOAc}(\mathrm{pH} 4.5 ; 0.5 \mathrm{~mL})$. An aliquot of the resulting solution $(200 \mu \mathrm{L})$ was added to a mixture of $6 \mu \mathrm{L} 0.01 \mathrm{M} \mathrm{AlCl}_{3}$ in $0.05 \mathrm{M} \mathrm{NaOAc}(\mathrm{pH} 4$ and $50 \mu \mathrm{g}$ Glu-NH-CO-NH-Lys(Ahx-HBED-CC) (PSMA-11) in $200 \mu \mathrm{L} \mathrm{EtOH}$. The reaction mixture was allowed to stir at $100{ }^{\circ} \mathrm{C}$ for $5 \mathrm{~min}$. After cooling to room temperature the crude product was passed through a HLB column, which was washed with $\mathrm{NaOAc}$ buffer $(10 \mathrm{~mL}, \mathrm{pH}=4.3)$. The labeled product was eluted using 1:1 saline/EtOH $(2 \mathrm{~mL}) \cdot\left[\mathrm{Al}^{18} \mathrm{~F}\right]$ PSMA-11 was prepared in $65-70 \% \mathrm{RCY}$. Analytical HPLC conditions were as follows: eluent: $5 \%$ for $3 \mathrm{~min}$, then $50 \%$ for $7 \mathrm{~min}$; flow rate: $3 \mathrm{~mL} / \mathrm{min}$; column: Chromolith ${ }^{\circ}$ SpeedROD RP-18e column (Merck, Darmstadt, Germany), $50 \times 4.6 \mathrm{~mm}$; retention time: $\left[\mathrm{Al}^{18} \mathrm{~F}\right]$ PSMA-11 $5.7 \mathrm{~min}$.

\section{Experimental animals}

Animal experiments were carried out in accordance with the EU directive 2010/63/EU and the German Animal Welfare Act (TierSchG, 2006), and were approved by regional authorities (Ministry for Environment, Agriculture, Conservation and Consumer Protection of the State of North Rhine-Westphalia). Fourteen healthy male rats (6 Wistar, 7 Long Evans; Janvier Labs, Le Genest-Saint-Isle, France and Harlan Laboratories, Roßdorf, Germany; 380-635 g) and 5 male SCID mice (C.B-Igh-1b/IcrTac-Prkdcscid, Taconic, Hudson, USA; 18-19 g) were used. Rats were housed in pairs, mice in groups of 2-3 in individually ventilated cages (NexGen Ecoflo, Allentown Inc., Allentown, NJ, USA) under controlled ambient conditions $\left(22 \pm 1{ }^{\circ} \mathrm{C}\right.$ and $55 \pm 5 \%$ relative humidity). Food and water were available at all times. For tumor xenografts, a suspension of LNCaP cells ( $5 \times 10^{6}$ in $150 \mu \mathrm{L}$ matrigel) was injected subcutaneously in to the scruff of the neck between the shoulders of the mice. After 3 weeks, the mice developed subcutaneous tumors with volumes of about $1 \mathrm{~cm}^{3}$. The health status of all animals was monitored daily and was stable throughout the experiments. After completion of the measurements, the tumor-bearing mice were sacrificed by cervical dislocation. Apart from the one rat used for autoradiography, the rats were not sacrificed and remained in our animal facility.

\section{PET}

A small animal PET/SPECT/CT scanner (Triumph II, Trifoil, USA) and a stand-alone small animal PET scanner (Focus 220, Siemens) were used. The tracer was injected during a short anesthesia (2\% isoflurane in 30\% oxygen $/ 70 \%$ air $)$ into the lateral tail vein $\left(\left[{ }^{18} \mathrm{~F}\right] \mathrm{DCFPyL}\right.$ : 14-71 MBq, $n=6$ ); $\left[\mathrm{Al}^{18} \mathrm{~F}\right]$ PSMA-11: $25-54 \mathrm{MBq}, n=3$; $\left[{ }^{68} \mathrm{Ga}\right]$ PSMA-11: $\left.13-51 \mathrm{MBq}, \quad n=3\right)$. Additionally, in three rats, $\left[{ }^{18} \mathrm{~F}\right] \mathrm{DCFPyL}$ was injected together with the PSMA inhibitor, 2-(phosphonomethyl)pentane-1,5-dioic acid (2-PMPA; $23 \mathrm{mg} / \mathrm{kg})$.

Imaging started $60 \mathrm{~min}$ after tracer injection and ended $120 \mathrm{~min}$ after injection. Animals were fixed in an animal holder with anesthesia mask ( $2 \%$ isoflurane in $30 \%$ oxygen $/ 70 \%$ air). Breathing rate and body temperature were monitored and held at approx. 60 breaths/min and $37^{\circ} \mathrm{C}$, respectively. Focus 220 emission scans were followed by an $8 \mathrm{~min}$ transmission scan with a rotating ${ }^{57} \mathrm{Co}$-point source, Triumph II emission scans by a $10 \mathrm{~min} C \mathrm{CT}$ scan $(70 \mathrm{kV}, 500 \mu \mathrm{A})$. The rats were sacrificed at the following day, and dorsal root ganglia 
were removed and fixed overnight in $4 \%$ paraformaldehyde in PBS (pH 7.4) for immunohistochemistry.

For mouse scans $(n=5)$, the Triumph II PET/SPECT/ CT scanner was used, and 21-32 MBq of $\left[{ }^{18} \mathrm{~F}\right]$ DCFPyL were injected i.v. Imaging procedure was as described above.

Following Fourier rebinning, data were reconstructed to single-frame summed images using an iterative OSEM3D/MAP procedure including attenuation and decay correction. Data analysis was performed with the help of the software VINCI 4.92 (Max Planck Institute for Metabolism Research, Cologne, Germany). Rat images were Gauss filtered ( $1 \mathrm{~mm}$ FWHM), mouse images remained unfiltered. $\mathrm{SUV}_{\mathrm{BW}}$ was determined according to the following equation:

$$
\begin{aligned}
\mathrm{SUV}_{\mathrm{BW}}= & \text { image radioactivity }[\mathrm{Bq} / \mathrm{g}] \\
& \times \text { body weight }[\mathrm{g}] \\
& \times 100 / \text { injected dose }[\mathrm{Bq}]
\end{aligned}
$$

Elliptical volumes of interest (VOIs) were drawn to extract mean $\mathrm{SUV}_{\mathrm{BW}}$ values for the rat trigeminal and superior cervical ganglia $\left(9 \mathrm{~mm}^{3}\right)$ and the mouse subcutaneous tumors (36-444 $\mathrm{mm}^{3}$, depending on tumor size). Background activity for calculation of signal-to-noise ratio was measured dorsal from the cervical vertebral column with a $390 \mathrm{~mm}^{3}$ VOI. For comparison of tracer uptake in the left and right superior cervical ganglion (SCG) of the same animal $(n=6$ for $\left[{ }^{18} \mathrm{~F}\right]$ DCFPyL, $n=3$ for $\left[{ }^{68} \mathrm{Ga}\right]$ PSMA-11), the SCG with the higher mean $\mathrm{SUV}_{\mathrm{BW}}$ was set to $100 \%$, and the other SCG was proportioned accordingly (e.g. left SCG: 100\%; right SCG: 98\%). Side-specific mean values were calculated across animals.

\section{Autoradiography}

Autoradiography of $\left[{ }^{18} \mathrm{~F}\right] \mathrm{DCFPyL}$ accumulation in rat dorsal root ganglia was performed with one healthy rat (635 g body weight). $70.5 \mathrm{MBq} \quad\left[{ }^{18} \mathrm{~F}\right] \mathrm{DCFPyL}$ were injected during a short anesthesia (2\% isoflurane in 30\% oxygen $/ 70 \%$ air) into the lateral tail vein. After $1 \mathrm{~h}$ of awake uptake the rat was sacrificed by cervical dislocation under anesthesia, and the cervical/thoracal spinal cord was extracted. Longitudinal sections of $50 \mu \mathrm{m}$ thickness were cut on a cryostat and placed on a microscope slide. The sections were covered with scintillator foil and measured with a dFINE Betaimager (Biospace Lab, Paris, France) for $2 \mathrm{~h}$.

\section{Immunohistochemistry}

Consecutive formalin-fixed, paraffin-embedded longitudinal tissue sections ( $2 \mu \mathrm{m}$ thick) of dorsal root ganglia were dewaxed in xylene and rehydrated through graded concentrations of ethanol to distilled water. Sections were then immersed in $10 \mathrm{~mm}$ sodium citrate buffer ( $\mathrm{pH}$ 6.0) and processed for antigen retrieval in the microwave oven at $600 \mathrm{~W}$ for $5 \mathrm{~min}$. For blocking of endogenous peroxidase activity, the sections were treated with $0.3 \% \mathrm{H}_{2} \mathrm{O}_{2}$ solution for $15 \mathrm{~min}$ at ambient
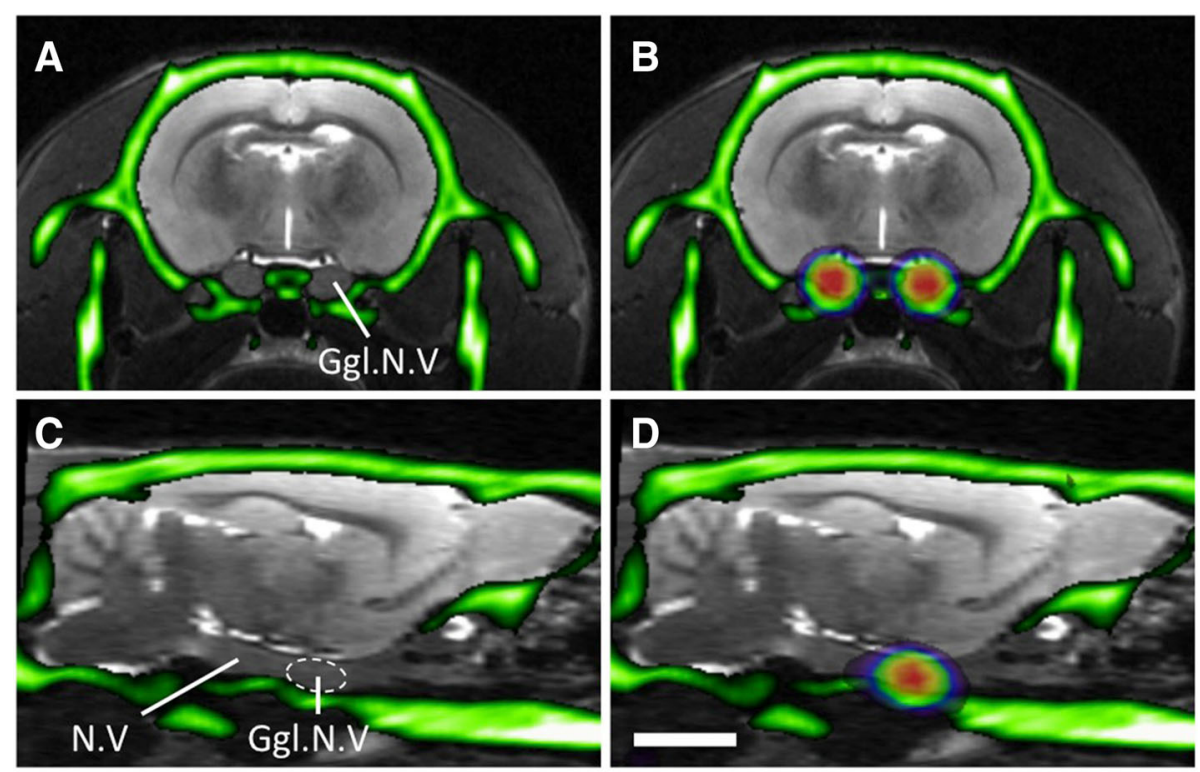

SUV $\mathrm{B}_{\text {BW }} 15$ 50

Fig. $1\left[{ }^{18}\right.$ F $]$ DCFPyl accumulation in the trigeminal ganglion. (a) + (c): Overlay of the CT image (green) and an MRI template (grey) in the transverse (a) and sagittal plane (c). (b) + (d): Overlay between CT (green), MRI (grey) and PET (colored). Abbreviations: Ggl.N.V: trigeminal ganglion; N.V: trigeminal nerve. Scale bar: $5 \mathrm{~mm}$ 
temperature. Unspecific antibody binding was inhibited by incubation in 3\% BSA-TBST solution for $30 \mathrm{~min}$ at ambient temperature. For staining, sections were incubated with the anti-PSMA antibody (1:200 dilution in TBST, clone YPSMA-1, Abcam plc, Cambridge, UK) overnight at $4{ }^{\circ} \mathrm{C}$. Subsequently, the sections were washed tree times with TBST and exposed for $60 \mathrm{~min}$ to peroxidase-linked anti-mouse immunoglobulin antibody (1:500 diluted in TBST, Cell Signaling Technology Europe B.V., Frankfurt-Main, Germany). Color development was performed using diaminobenzidine and sections were counterstained with haematoxylin/eosin.

\section{Statistical analysis}

All statistical analyses were performed with Prism 6.0f for Mac OS X. Biodistribution of tracers was compared using One-way ANOVA followed by Dunnett's multiple comparison test. Correlation between tumor tracer uptake and tumor size was assessed with the Pearson correlation test. Variances of tracer uptake in mouse tumor xenografts and rat SCG were compared with an F-Test for unequal variance.

\section{Results}

Biodistribution of PSMA specific tracers in healthy rats In healthy rats, $\left[{ }^{18} \mathrm{~F}\right] \mathrm{DCFPyL}$ accumulated in peripheral ganglia with the highest uptake in the ganglion of the trigeminal nerve $\left(37.9 \pm 9.9 \mathrm{SUV}_{\mathrm{BW}}\right.$, measured 60-120 min after injection; $n=6$; Fig. 1 ). The eight focal accumulations of radioactivity detected in the cervical intervertebral foramina were assigned to the dorsal root ganglia (Figs. 2a-e, 3a, 4). Autoradiography confirmed that dorsal root ganglia, but not the spinal cord or the spinal nerves, accumulated $\left[{ }^{18} \mathrm{~F}\right] \mathrm{DCFPyL}$ (Fig. 2f-h). Radioactivity accumulation was also visible in the stellate ganglion, salivary glands and heart (Fig. 3a). The uptake of $\left[{ }^{18} \mathrm{~F}\right] \mathrm{DCFPyL}$ in the SCG was 20.2 $\pm 5.8 \mathrm{SUV}_{\mathrm{BW}}$ and the signal-to-noise ratio was $6.7 \pm 2.6$. Co-application with 2-PMPA strongly decreased radioactivity accumulation in the SCG (Fig. 3b; $4.6 \pm 1.8 \mathrm{SUV}_{\mathrm{BW}}$ ) and also in other PSMA-positive tissues, whereas radioactivity enrichment in the liver was only slightly reduced $\left(\left[{ }^{18} \mathrm{~F}\right] \mathrm{DCFPyL}\right.$ vs. $\left[{ }^{18} \mathrm{~F}\right] \mathrm{DCFPyL}+2$-PMPA: $65.3 \pm 21.7$ vs. 47.0 \pm 7.7 $\mathrm{SUV}_{\mathrm{BW}}$, see also Table 1).

$\left[\mathrm{Al}^{18} \mathrm{~F}\right]$ PSMA-11 suffered from substantial in vivo defluorination (Fig. 3c) reflected by high radioactivity
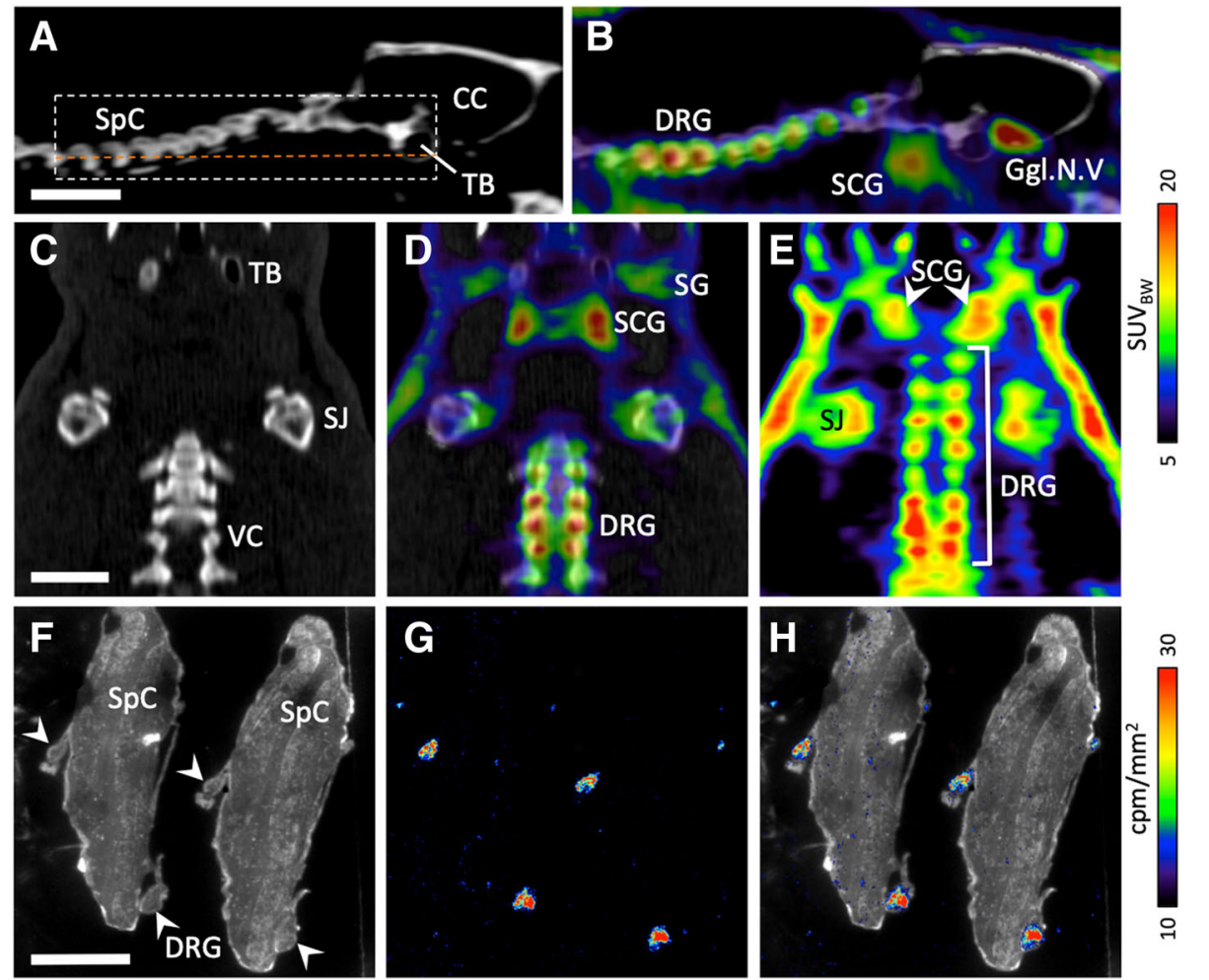

Fig. $2\left[{ }^{18}\right.$ F DCFPyL accumulation in dorsal root and autonomic ganglia. (a): Sagittal CT image of a rat skull and neck. (b): Overlay of PET and CT (sagittal). (c): Horizontal CT image of neck and shoulder region (along the orange dashed line in a). (d): Overlay of PET and CT (horizontal). (e): Sum of ten horizontal planes of the PET image, indicated by the box in (a). (f): Two longitudinal adjacent sections of a rat spinal cord. Dorsal root ganglia are indicated by arrowheads. (g): Autoradiographic image of spinal cord sections. (h): Overlay of microscopic and autoradiographic image. Abbreviations: CC: cranial cavity; DRG: dorsal root ganglia; Ggl.N.V.: ganglion of the trigeminal nerve; SCG: superior cervical ganglion; SG: salivary gland; SJ: shoulder joint; SpC: spinal cord; TB: tympanic bulla; VC: vertebral column. Scale bars: $1 \mathrm{~cm}$ in (a)-(e), $5 \mathrm{~mm}$ in (f)-(h) 

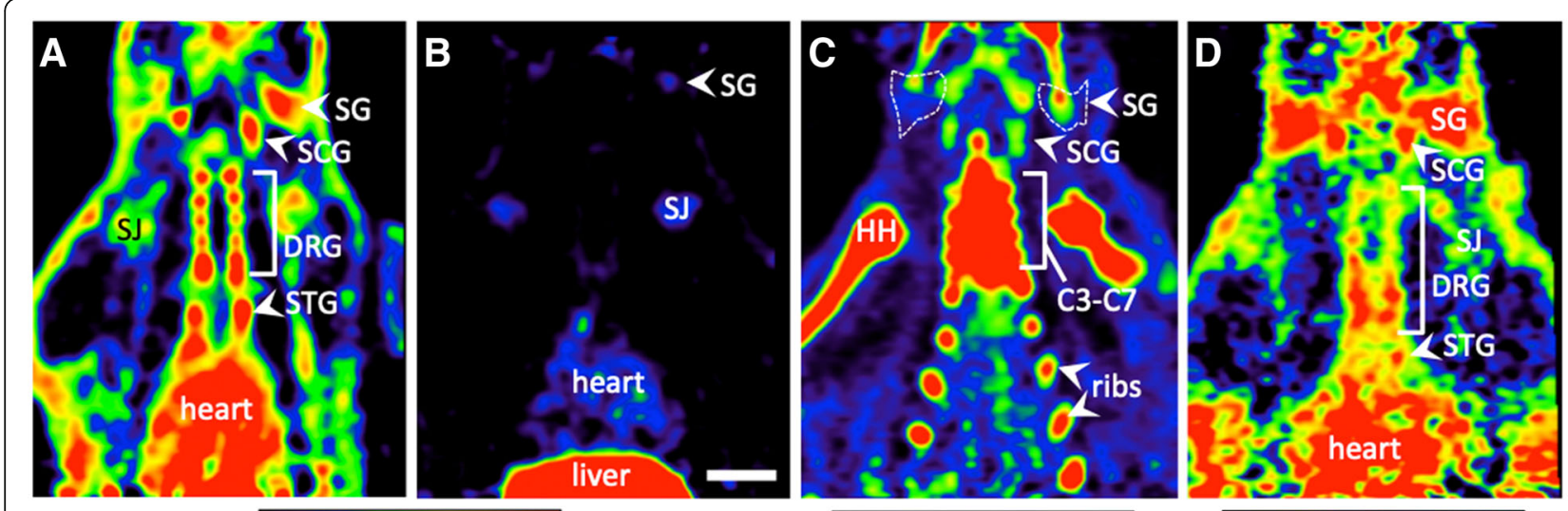

E

$$
\text { SUV }_{\text {BW }}: 2
$$

\section{3}

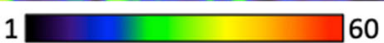

8
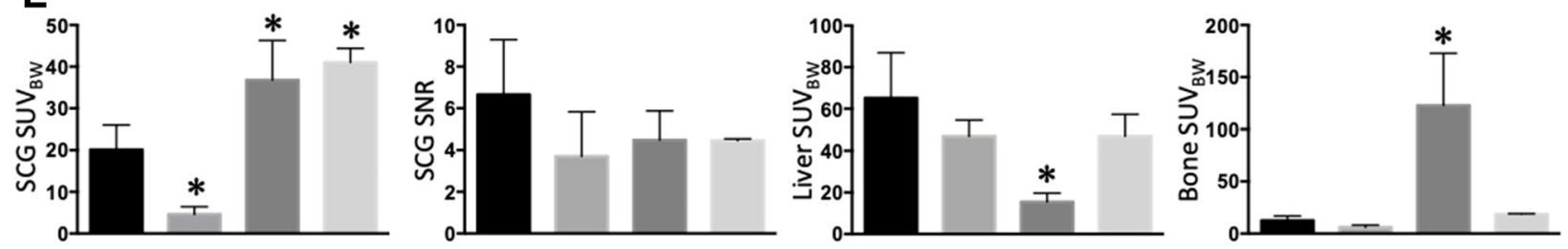

$\mathbf{F}^{[18 \mathrm{~F}] \mathrm{DCFPyL}(\mathrm{n}=6)} \square\left[{ }^{18} \mathrm{~F}\right]$ DCFPy

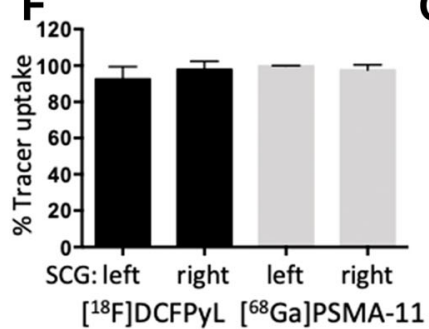

G Rat 1
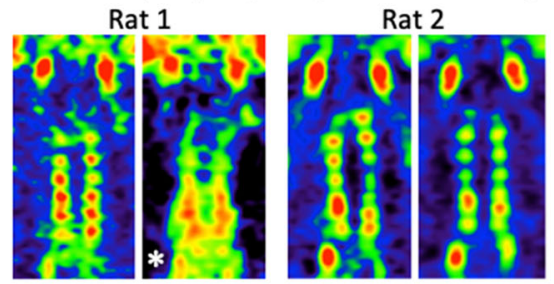

Rat 3

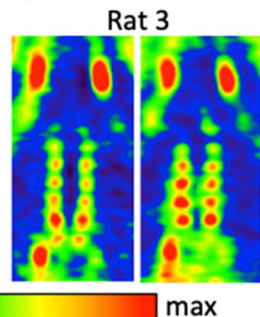

$\min$

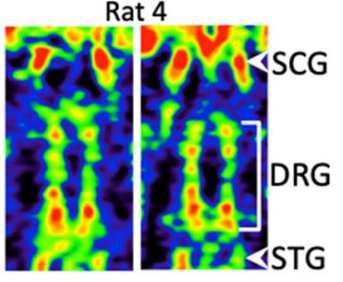

Fig. 3 Cervical ganglia in healthy rats for validation of PSMA ligands. (a): Biodistribution of $\left[^{18} \mathrm{~F}\right] \mathrm{DCFPyL}$, horizontal plane. (b): Blocking experiment with $\left[{ }^{18} \mathrm{~F}\right]$ DCFPyL + 2-PMPA (23 mg/kg). (c): Biodistribution of $\left[\mathrm{Al}{ }^{18} \mathrm{~F}\right] \mathrm{PSMA}-11$; high accumulation in bones reflected substantial defluorination. (d): Biodistribution of $\left[{ }^{68} \mathrm{Ga}\right] P S M A-11$. (e): Quantitative analysis of SCG tracer uptake, SCG signal-to-noise ratio, liver and bone (sternum) uptake. See also Table 1. (f): Similarity of tracer uptake in left and right SCG, shown for $\left[{ }^{18} \mathrm{~F}\right] \mathrm{DCFPyL}\left(n=6\right.$, black bars) and $\left.{ }^{68} \mathrm{Ga}\right] \mathrm{PSMA}-11$ ( $n=3$, gray bars). (g): Four rats with two PSMA-PET measurements on different days, demonstrating stability of the ganglionic PSMA pattern. The second measurement in rat 1 was with $\left[{ }^{68} \mathrm{Ga}\right] P S M A-11$, all others with ${ }^{18}$ F-labeled PSMA tracers $(*)$. Abbreviations: C3-C7: cervical vertebrae 3-7; DRG: dorsal root ganglia; HH: humeral head (bone); SCG: superior cervical ganglion; SG: salivary gland; SJ: shoulder joint (cartilage); SNR: signal-to-noise ratio; STG: stellate ganglion. Scale bar: $1 \mathrm{~cm}$

uptake in bone $\left(122.8 \pm 50.1 \mathrm{SUV}_{\mathrm{BW}} ; \mathrm{F}(3,11)=21.1\right.$ $p<0.0001$; post-hoc $p<0.05$ ). This bone uptake conceals tracer accumulation in the dorsal root ganglia which are embedded within the vertebrae. Nevertheless, tracer uptake in the SCG $\left(36.8 \pm 9.5 \mathrm{SUV}_{\mathrm{BW}}\right.$; Fig. 3e) was significantly higher compared to $\left[{ }^{18} \mathrm{~F}\right] \mathrm{DCFPyL}(20.2 \pm 5.8$ $\operatorname{SUV}_{\mathrm{BW}} ; \mathrm{F}(3,11)=24.8 ; p<0.0001$; post-hoc $\left.p<0.05\right)$, while signal-to-noise ratio was insignificantly lower $(4.5 \pm$ 1.4 vs. $6.7 \pm 2.6$; $\mathrm{F}(3,11)=1.7, p=0.2167)$. Liver uptake of $\left[\mathrm{Al}^{18} \mathrm{~F}\right] \mathrm{PSMA}-11$ was significantly lower $(15.5 \pm 4.2$ $\left.\mathrm{SUV}_{\mathrm{BW}}\right)$ compared to $\left[{ }^{18} \mathrm{~F}\right] \mathrm{DCFPyL}\left(65.3 \pm 21.7 \mathrm{SUV}_{\mathrm{BW}} ; \mathrm{F}\right.$ $(3,11)=6.7 ; p=0.0079$; post-hoc $p<0.05)$.

PET images obtained with $\left[{ }^{68} \mathrm{Ga}\right]$ PSMA-11 were more blurry with the overall background higher compared to that observed with the ${ }^{18}$ F-labeled tracers (Fig. 3d). While $\left[{ }^{68} \mathrm{Ga}\right]$ PSMA-11 uptake in the SCG $(41.0 \pm 3.4$
$\mathrm{SUV}_{\mathrm{BW}}$ ) was significantly higher compared to $\left[{ }^{18} \mathrm{~F}\right] \mathrm{DCFPyL}$, signal-to-noise ratio $(4.5 \pm 0.1)$ was lower and similar to that of $\left[\mathrm{Al}^{18} \mathrm{~F}\right] \mathrm{PSMA}-11$. Left and right SCG showed similar uptake of $\left[{ }^{18} \mathrm{~F}\right] \mathrm{DCFPyL}$ and $\left[{ }^{68} \mathrm{Ga}\right]$ PSMA-11 (Fig. 3f). When measured twice in the same animal, even with two different PSMA tracers, the individual shape of the SCG and dorsal root ganglia chain was clearly identifyable (Fig. 3g).

\section{Immunohistochemistry}

Immunohistochemistry of dorsal root ganglia with a PSMA-specific antibody revealed that immunoreactivity was confined to the satellite glial cells, but absent in neurons (Fig. 4d). This finding confirms that the accumulation of radioactivity observed in the peripheral 

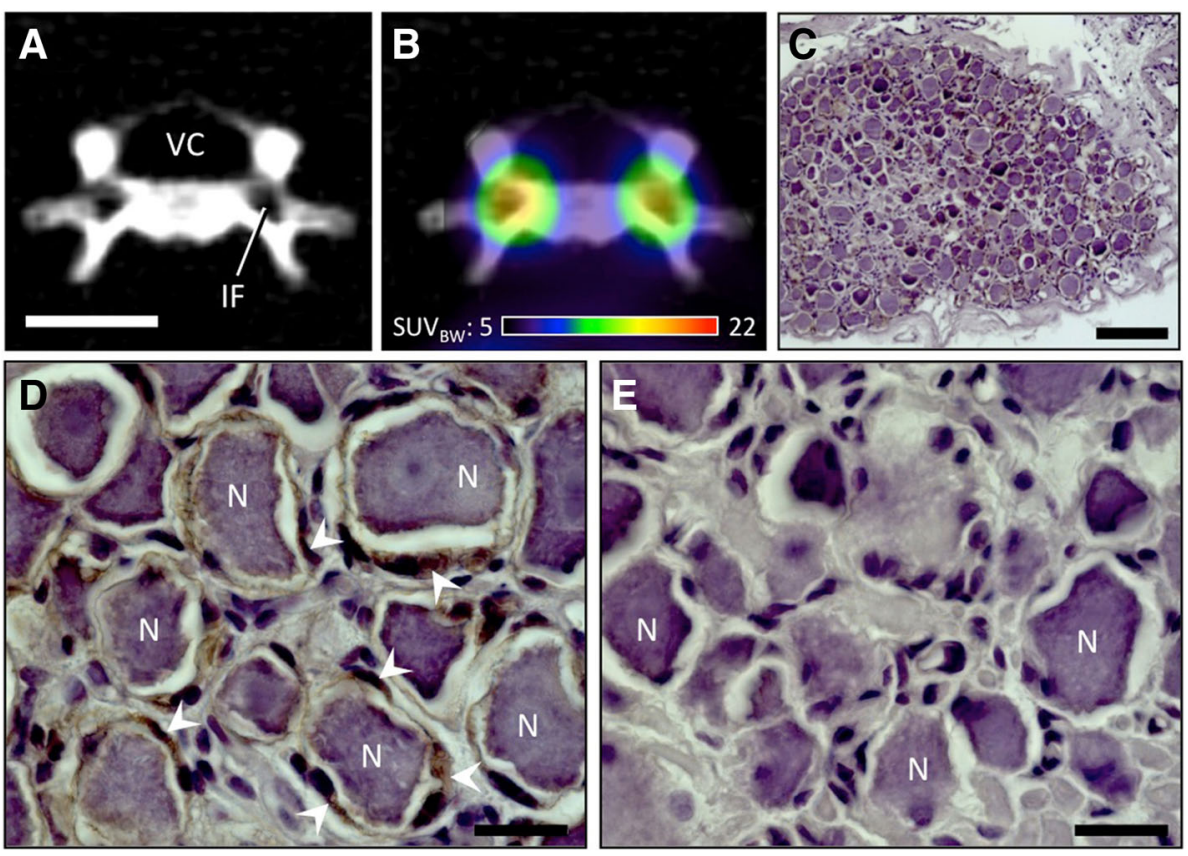

Fig. 4 Localization of PSMA in dorsal root ganglia. (a): Transverse section through a CT image of the spinal column, between cervical vertebrae C6 and C7. (b): Overlay of PET and CT, showing tracer accumulation in the intervertebral foramina, where dorsal root ganglia are localized. (c): Overview of a dorsal root ganglion section, stained with H\&E and anti-PSMA, corresponding to the radioactivity accumulation in the intervertebral foramen. (d): Zoomed fragment of (c), showing PSMA-immunostaining in satellite glial cells (arrowheads). (e): Control staining without primary antibody. Abbreviations: N: neuron; IF: intervertebral foramen; VC: vertebral canal. Scale bars: $5 \mathrm{~mm}$ in (a) $+(\mathbf{b}), 25 \mu \mathrm{m}$ in $(\mathbf{c})$ and $5 \mu \mathrm{m}$ in (d) $+(\mathbf{e})$

ganglia (Fig. 4b) reflects PSMA expression in the ganglionic satellite cells.

\section{Comparison with LNCaP xenografted mice}

In LNCaP xenografted mice, peripheral ganglia were also discernible, but were too small to provide delineated structures. Although LNCaP cells were inoculated on the same day, tumor sizes varied considerably $\left(36-444 \mathrm{~mm}^{3}\right)$. Tumor xenografts showed a heterogeneous uptake of $\left[{ }^{18}\right.$ F]DCFPyL (Fig. 5a). Therefore, we used the voxel with highest activity $\mathrm{SUV}_{\mathrm{BW} \max }$ rather than the mean value of the whole tumor VOI. $\left[{ }^{18} \mathrm{~F}\right] \mathrm{DCFPyL}$ accumulation ranged from 6.2 $\mathrm{SUV}_{\mathrm{BWmax}}$ to $155.8 \mathrm{SUV}_{\mathrm{BWmax}}$ depending on tumor size $(R=0.97 ; p=0.0073$; equation of regression line: $y=0.3377 x-12.66$; Fig. $5 b)$. Signal-to-noise ratio was $5.8 \pm 4.2$. In small tumors $\left(<40 \mathrm{~mm}^{3}\right)$ maximum $\left[{ }^{18} \mathrm{~F}\right] \mathrm{DCFPyL}$ uptake was below $10 \mathrm{SUV}_{\mathrm{BW}}$. According to the regression equation, tumors must reach a volume of $58 \mathrm{~mm}^{3}$ to achieve a maximum tracer uptake of 20.2 $\mathrm{SUV}_{\mathrm{BW}}$, the average value measured for the rat SCG. The latter have a much smaller volume of approx. 9 $\mathrm{mm}^{3}$. Due to different tumor sizes, the variance of $\left[{ }^{18} \mathrm{~F}\right]$ DCFPyL uptake in the mouse tumor xenografts was significantly higher compared to that in rat SCGs $(\mathrm{F}(4,5)=78.4, p=0.0002$; Fig. 5c).

\section{Discussion}

Our results demonstrate that PSMA-targeted probes significantly accumulate in the rat peripheral ganglia due to specific binding to PSMA expressing satellite cells. Therefore, this structure might be used as a reference organ in the evaluation of PSMA ligands.

Table 1 Accumulation of PSMA tracers in different tissues

\begin{tabular}{llllll}
\hline & $\mathrm{n}$ & $\mathrm{SCG}, \mathrm{SUV}_{\mathrm{BW}}$ & $\mathrm{SNR}$ & Liver, SUV & Bone, SUV \\
\hline$\left[{ }^{18} \mathrm{~F}\right] \mathrm{BW}$ CFPyL & 6 & $20.2 \pm 5.8$ & $6.7 \pm 2.6$ & $65.3 \pm 21.7$ & $12.4 \pm 4.3$ \\
{$\left[{ }^{18} \mathrm{~F}\right] \mathrm{DCFPyL}+2-\mathrm{PMPA}$} & 3 & $4.6 \pm 1.8^{*}$ & $3.7 \pm 2.1$ & $47.0 \pm 7.7$ & $6.1 \pm 1.9$ \\
{$\left[\mathrm{Al}{ }^{18} \mathrm{~F}\right]$ PSMA-11 } & 3 & $36.8 \pm 9.5^{*}$ & $4.5 \pm 1.4$ & $15.5 \pm 4.2^{*}$ & $122.8 \pm 50.1^{*}$ \\
{$\left[{ }^{68} \mathrm{G}\right.$ ]PSMA-11 } & 3 & $41.0 \pm 3.4^{*}$ & $4.5 \pm 0.1$ & $47.0 \pm 10.4$ & $18.5 \pm 0.61$ \\
ANOVA main effect & & $\mathrm{F}(3,11)=24.8 p<0.0001$ & $\mathrm{~F}(3,11)=1.7 p=0.2167$ & $\mathrm{~F}(3,11)=6.7 p=0.0079$ & $\mathrm{~F}(3,11)=21.1 p<0.0001$
\end{tabular}

Abbreviations: SCG: superior cervical ganglion, SNR signal-to-noise ratio measured for SCG. *Significantly different from $\left[{ }^{18} \mathrm{~F}\right] \mathrm{DCFPyL} ; p<0.05$ in Dunnett's multiple comparison test 


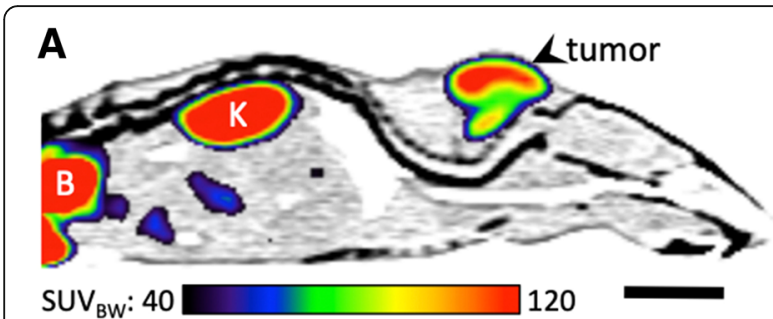

B
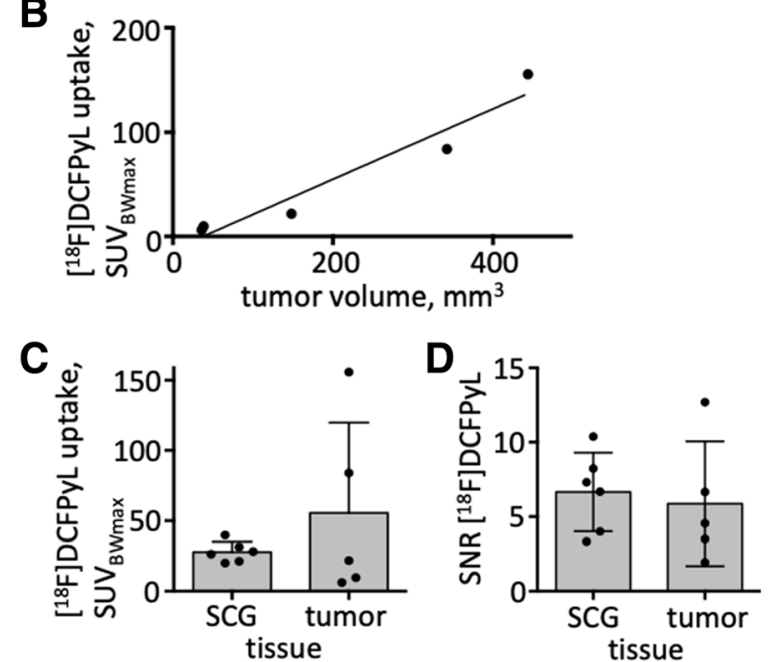

Fig. 5 LNCaP PCa xenograft bearing mice. (a): $\left[{ }^{18} \mathrm{~F}\right] \mathrm{DCFPyL}$, sagittal plane. (b): Maximal $\left.{ }^{18} \mathrm{~F}\right] \mathrm{DCFPyL}$ uptake (tumor voxel with highest intensity) plotted against tumor volume in five mice $(R=0.97$, $p=0.0073)$. (c): Maximal $\left[{ }^{18} \mathrm{~F}\right] \mathrm{DCFPyL}$ uptake in the rat SCG compared to mouse tumor xenografts. Shown are mean \pm standard deviation as well as individual data points. Variance was significantly higher in tumors compared to SCG $(F(4,5)=78.4, p=0.0002)$. (d): Signal-to-noise ratio measured with $\left.{ }^{18} \mathrm{~F}\right] \mathrm{DCFPyL}$ in rat SCG and mouse tumor xenografts. There was no significant difference between the two models. Abbreviations: B: bladder; K: kidney; SCG: superior cervical ganglion. Scale bar: $1 \mathrm{~cm}$

The rat superior cervical ganglia are easy-to-recognize tissues which fit in the axial field of view of typical $\mu$ PET scanners together with the cervical dorsal root ganglia, heart and the frontal part of the liver. They are located far from any bone structures. Therefore, the sufficient spatial separation should exclude the possibility of significant "spillover" effects and allow quantification even in the case of tracer defluorination resulting in high accumulation of radioactivity in bone. Consequently, we choose SCG as a reference tissue for the exemplary comparative evaluation of PSMA ligands.

Our study showed significant differences between the tracers with regard to their image parameters. $\left[{ }^{18} \mathrm{~F}\right] \mathrm{DCFPyL}$ provided high quality visualization of the SCG with high signal-to-noise ratio. PSMA specificity of the uptake was confirmed by blocking experiments. Accumulation of $\left[{ }^{68} \mathrm{Ga}\right] \mathrm{PSMA}-11$ in the SCG was significantly higher compared to $\left[{ }^{18} \mathrm{~F}\right] \mathrm{DCFPyL}$, whereas signal-to-noise ratio was comparable. The main difference between the two tracers was the lower perceived quality of images obtained with $\left[{ }^{68} \mathrm{Ga}\right]$ PSMA-11 presumably owing to longer positron range of ${ }^{68} \mathrm{Ga}$ compared to that of ${ }^{18} \mathrm{~F}$, as well as to scattered photons originating from high energy emission photons of ${ }^{68} \mathrm{Ga}$ [35], but also higher background activity. Superior image quality of $\left[{ }^{18} \mathrm{~F}\right] \mathrm{DCFPyL}$ due to low beta energy of ${ }^{18} \mathrm{~F}$ was already described in patients $[8,36]$. This effect was even more pronounced in small animals.

$\left[\mathrm{Al}^{18} \mathrm{~F}\right]$ PSMA-11 combines the convenient half-life and low beta energy of ${ }^{18} \mathrm{~F}$ with the high PSMA affinity of $\left[{ }^{68} \mathrm{Ga}\right.$ ]PSMA-11 [29]. While the excellent properties of $\left[\mathrm{Al}^{18} \mathrm{~F}\right] \mathrm{PSMA}-11$ with high SCG tracer accumulation and low liver retention (significantly higher and lower than those of $\left[{ }^{18} \mathrm{~F}\right] \mathrm{DCFPyL}$, respectively) could be confirmed, we also observed high radioactivity uptake in bones attributed to extensive tracer defluorination. Whereas no substantial defluorination of $\left[\mathrm{Al}^{18} \mathrm{~F}\right] \mathrm{PSMA}$ 11 in vivo had been reported in earlier studies [29, 30], Ginglio et al. recently observed relatively rapid defluorination of the tracer in vitro in human serum with halftime of $2.5 \mathrm{~h} \mathrm{[31].}{ }^{18} \mathrm{~F}$-Fluoride avidly accumulates in PCa bone lesions [37], but also in healthy bones. This could lead to incorrect diagnosis and wrong therapy.

In the LNCaP tumor xenograft SCID mouse model, $\left[{ }^{18} \mathrm{~F}\right] \mathrm{DCFPyL}$ uptake linearly correlated with tumor size. This effect was described also for another PSMA ligand, $\left[{ }^{64} \mathrm{Cu}\right] \mathrm{CBT} 2 \mathrm{G}$ [38], and can presumably be attributed to poor vascularization [15] and, consequently, low blood supply of small tumor xenografts. Therefore, PSMA tracers should be evaluated in animals bearing xenografts of similar volumes to avoid inconsistent uptake data (Fig. 4c). Our results have shown that tumors require a size of $58 \mathrm{~mm}^{3}$ to match the $\left[{ }^{18} \mathrm{~F}\right] \mathrm{DCFPyL}$ uptake of the SCG. Although peripheral ganglia are small $(<10$ $\mathrm{mm}^{3}$ ), they are rather densely vascularized [39], similar to metastases $>1 \mathrm{~mm}^{3}$ [40]. Therefore inter-individual variance of tracer accumulation in ganglia was low. The variance can be further reduced by application of the same healthy rats for the evaluation of several PSMA tracers. This is infeasible in tumor xenograft-bearing animals owing to the continuous tumor growth and tumor size-associated structural and metabolic tissue changes.

\section{Conclusions}

While PSMA-expression in ganglia had been regarded as an important pitfall in prostate carcinoma-PET diagnostics [17] and had not found any practical use, we explored this phenomenon for the evaluation of $\mathrm{PCa}$ imaging agents in healthy rats.

We demonstrated the applicability of the peripheral ganglia of healthy rats as a non-invasive and inexpensive 
native model of small PCa lesions. Furthermore, our study revealed the non-inferiority of the novel model compared to conventionally used tumor xenografts in immune compromised rodents with regard to reproducibility and stability of the PSMA signal. The SCGs were always accessible for quantification of tracer uptake independently from tracer defluorination. The cervical dorsal root ganglia were also easily identifiable provided the radioligand was metabolically stable and defluorination did not occur. In contrast to the tumor xenograft model, where PSMA-specific uptake correlated linearly with tumor size, inter- and intra-individual variance of tracer accumulation in ganglia was low. Importantly, tumor burden-associated pain and adverse effects were avoided entirely. To the best of our knowledge, this is the first tumor-free model suitable for the in vivo evaluation of tumor imaging agents.

\section{Abbreviations}

[ ${ }^{18}$ F]DCFPyL: 2-(3-\{1-carboxy-5-[(6-[(18)F]fluoro-pyridine-3-carbonyl)-amino]pentyl\}-ureido)-pentanedioic acid; 2-PMPA: 2-(phosphonomethyl)pentane-1,5dioic acid; BW: Body weight; CT: Computed tomography; EOB: End of bombardement; HPLC: High performance liquid chromatography; LNCaP: Lymph node carcinoma of the prostate; MRI: Magnetic resonance imaging; NAAG: N-acetylaspartylglutamate; PBS: Phosphate buffered saline; PCa: Prostate carcinoma; PET: Positron emission tomography; PSMA: Prostatespecific membrane antigen; RCY: Radiochemical yield; SCID: Severe combined immunodeficiency; SPECT: Single photon emission computed tomography; SUV: Standardized uptake value; VOI: Volume of interest

\section{Acknowledgements}

Not applicable.

\section{Author's contributions}

$A M, B Z, H E, B N$ and FM designed the study. BZ, PK, JZ, RR, SMV and BN did radiochemistry and tracer synthesis. $\mathrm{HE}$ and $\mathrm{AM}$ performed the PET measurements. AM conducted the histochemistry. HE did autoradiography. $\mathrm{HE}$ analyzed the data and prepared the figures. AM, BZ, HE, BN and FM wrote the manuscript. All authors read and approved the final manuscript.

\section{Funding}

This study was funded by the LeitmarktAgentur.NRW and the European Regional Development Fund (grant numbers LS-1-2-023C/EFRE-0800973 and LS-1-2-023b/EFRE-0800992), and by the ERS seed fund RWTH Aachen (grant number OPSF 352). They provided financial support for tangible means and human resources. The funding body had no role in the design of the study or collection, analysis, and interpretation of data or in writing the manuscript.

\section{Availability of data and materials}

The datasets used and/or analysed during the current study are available from the corresponding author on reasonable request.

\section{Ethics approval and consent to participate}

Animal experiments were carried out in accordance with the EU directive 2010/63/EU and the German Animal Welfare Act (TierSchG, 2006), and were approved by regional authorities (Ministry for Environment, Agriculture, Conservation and Consumer Protection of the State of North RhineWestphalia).

\section{Consent for publication}

Not applicable.

\section{Competing interests}

The described procedure for the preparation of $\left[{ }^{18} \mathrm{~F}\right] \mathrm{DCFPyL}$ is the subject of a patent application by B. Zlatopolskiy, P. Krapf, R. Richarz, and B. Neumaier. There are no other potential conflicts of interest relevant for this article.

\section{Author details}

IInstitute of Radiochemistry and Experimental Molecular Imaging, University of Cologne, Faculty of Medicine and University Hospital Cologne, 50937 Cologne, Germany. ${ }^{2}$ Department of Nuclear Medicine, University of Cologne, Faculty of Medicine and University Hospital Cologne, 50937 Cologne, Germany. ${ }^{3}$ Forschungszentrum Jülich $\mathrm{GmbH}$, Institute of Neuroscience and Medicine, Nuclear Chemistry (INM-5), Wilhelm-Johnen-Straße, 52428 Jülich, Germany. ${ }^{4}$ Department of Nuclear Medicine, University Hospital, RWTH Aachen, Pauwelsstraße 30, Aachen 52074, Germany. ${ }^{5}$ Department of Radiology and Nuclear Medicine, Maastricht University Medical Center X, Maastricht, the Netherlands.

Received: 11 December 2018 Accepted: 16 June 2019 Published online: 26 June 2019

References

1. Bacich DJ, Ramadan E, O'Keefe DS, Bukhari N, Wegorzewska I, Ojeifo O, et al. Deletion of the glutamate carboxypeptidase II gene in mice reveals a second enzyme activity that hydrolyzes $\mathrm{N}$-acetylaspartylglutamate. J Neurochem. 2002;83(1):20-9.

2. Halsted $\mathrm{CH}$. Jejunal brush-border folate hydrolase. A novel enzyme. West J Med. 1991;155(6):605-9.

3. Ristau BT, O'Keefe DS, Bacich DJ. The prostate-specific membrane antigen: lessons and current clinical implications from 20 years of research. Urol Oncol. 2014;32(3):272-9.

4. Yao V, Bacich DJ. Prostate specific membrane antigen (PSMA) expression gives prostate cancer cells a growth advantage in a physiologically relevant folate environment in vitro. Prostate. 2006;66(8):867-75.

5. Conway RE, Rojas C, Alt J, Novakova Z, Richardson SM, Rodrick TC, et al. Prostate-specific membrane antigen (PSMA)-mediated laminin proteolysis generates a pro-angiogenic peptide. Angiogenesis. 2016;19(4):487-500.

6. Endepols H, Mottaghy FM, Simsekyilmaz S, Bucerius J, Vogt F, Winz O, et al. In vivo molecular imaging of glutamate carboxypeptidase II expression in re-endothelialisation after percutaneous balloon denudation in a rat model. Sci Rep. 2018;8(1):7411.

7. Kaittanis C, Andreou C, Hieronymus H, Mao N, Foss CA, Eiber M, et al. Prostate-specific membrane antigen cleavage of vitamin B9 stimulates oncogenic signaling through metabotropic glutamate receptors. J Exp Med. 2018;215(1):159-75.

8. Dietlein F, Kobe C, Neubauer S, Schmidt M, Stockter S, Fischer T, et al. PSAstratified performance of $18 \mathrm{~F}$ - and 68Ga-PSMA PET in patients with biochemical recurrence of prostate cancer. J Nucl Med. 2017;58(6):947-52.

9. Rowe SP, Drzezga A, Neumaier B, Dietlein M, Gorin MA, Zalutsky MR, et al. Prostate-specific membrane antigen-targeted radiohalogenated PET and therapeutic agents for prostate cancer. J Nucl Med. 2016;57(Suppl 3):90S-6S.

10. Verburg FA, Pfister D, Drude NI, Mottaghy FM, Behrendt FF. PSA levels, PSA doubling time, Gleason score and prior therapy cannot predict measured uptake of [68Ga]PSMA-HBED-CC lesion uptake in recurrent/metastatic prostate cancer. Nuklearmedizin. 2017;56(6):225-32.

11. Bouchelouche $K$, Turkbey B, Choyke PL. PSMA PET and radionuclide therapy in prostate cancer. Semin Nucl Med. 2016;46(6):522-35.

12. Filss C, Heinzel A, Miiller B, Vogg ATJ, Langen KJ, Mottaghy FM. Relevant tumor sink effect in prostate cancer patients receiving 177Lu-PSMA-617 radioligand therapy. Nuklearmedizin. 2018;57(1):19-25.

13. Afshar-Oromieh A, Babich JW, Kratochwil C, Giesel FL, Eisenhut M, Kopka K, et al. The rise of PSMA ligands for diagnosis and therapy of prostate cancer. J Nucl Med. 2016;57(Suppl 3):79S-89S.

14. Rea D, Del Vecchio V, Palma G, Barbieri A, Falco M, Luciano A, et al. Mouse models in prostate cancer translational research: from xenograft to PDX. Biomed Res Int. 2016;2016:9750795.

15. Simons BW, Brayton C. Challenges and limitations of mouse xenograft models of cancer. In: Uthamanthil RTP, de Stanchia E, editors. Patient derived tumor xenograft models: promise, potential and practice: Elsevier Inc; 2016. p. 25-36.

16. Krohn T, Verburg FA, Pufe T, Neuhuber W, Vogg A, Heinzel A, et al. [68Ga]PSMA-HBED uptake mimicking lymph node metastasis in coeliac ganglia: an important pitfall in clinical practice. Eur J Nucl Med Mol Imaging. 2015;42(2):210-4.

17. Rischpler C, Beck TI, Okamoto S, Schlitter AM, Knorr K, Schwaiger M, et al. (68)Ga-PSMA-HBED-CC uptake in cervical, coeliac and sacral ganglia as an important pitfall in prostate cancer PET imaging. J Nucl Med. 2018;59(9):1406-11. 
18. Werner RA, Sheikhbahaei S, Jones KM, Javadi MS, Solnes LB, Ross AE, et al. Patterns of uptake of prostate-specific membrane antigen (PSMA)targeted 18F-DCFPyL in peripheral ganglia. Ann Nucl Med. 2017;31(9):696-702.

19. Carozzi VA, Canta A, Oggioni N, Ceresa C, Marmiroli P, Konvalinka J, et al. Expression and distribution of 'high affinity' glutamate transporters GLT1, GLAST, EAAC1 and of GCPII in the rat peripheral nervous system. J Anat. 2008:213(5):539-46.

20. Berger UV, Carter RE, McKee M, Coyle JT. N-acetylated alpha-linked acidic dipeptidase is expressed by non-myelinating Schwann cells in the peripheral nervous system. J Neurocytol. 1995;24(2):99-109.

21. Aggarwal S, Ricklis RM, Williams SA, Denmeade SR. Comparative study of PSMA expression in the prostate of mouse, dog, monkey, and human. Prostate. 2006;66(9):903-10.

22. Gala JL, Loric S, Guiot Y, Denmeade SR, Gady A, Brasseur F, et al. Expression of prostate-specific membrane antigen in transitional cell carcinoma of the bladder: prognostic value? Clin Cancer Res. 2000;6(10):4049-54.

23. Rovenska M, Hlouchova K, Sacha P, Mlcochova P, Horak V, Zamecnik J, et al. Tissue expression and enzymologic characterization of human prostate specific membrane antigen and its rat and pig orthologs. Prostate. 2008;68(2):171-82.

24. Zlatopolskiy BD, Endepols H, Krapf P, Guliyev M, Urusova EA, Richarz R, et al. Discovery of 18F-JK-PSMA-7, a novel PET-probe for the detection of small PSMA positive lesions. J Nucl Med. 2018; in press.

25. Dietlein $M$, Hohberg M, Kobe C, Dietlein F, Zlatopolskiy BD, Krapf $P$, et al Performance of the novel 18F-labeled prostate-specific membrane antigenligand PSMA-7 for PET/CT in prostate cancer patients. J Nucl Med. 2018;59:452.

26. Hohberg M, Dietlein M, Kobe C, Dietlein F, Zlatopolskiy BD, Krapf P, et al. Biodistribution and radiation dosimetry of the novel 18F-labeled prostatespecific membrane antigen-ligand PSMA-7 for PET/CT in prostate cancer patients. J Nucl Med. 2018;59(Supplement 1:88.

27. Afshar-Oromieh A, Holland-Letz T, Giesel FL, Kratochwil C, Mier W, Haufe S, et al. Diagnostic performance of $\left({ }^{68}\right)$ Ga-PSMA-11 (HBED-CC) PET/CT in patients with recurrent prostate cancer: evaluation in 1007 patients. Eur J Nucl Med Mol Imaging. 2017:44(8):1258-68.

28. Chen Y, Pullambhatla M, Foss CA, Byun Y, Nimmagadda S. Senthamizhchelvan S, et al. 2-(3-\{1-Carboxy-5-[(6-[18F]fluoro-pyridine-3carbonyl)-amino]-pentyl\}-ureido)-pen tanedioic acid, [18F]DCFPyL, a PSMAbased PET imaging agent for prostate cancer. Clin Cancer Res. 2011;17(24):7645-53.

29. Malik N, Baur B, Winter G, Reske SN, Beer AJ, Solbach C. Radiofluorination of PSMA-HBED via Al18F(2+) chelation and biological evaluations in vitro. Mol Imaging Biol. 2015;17(6):777-85.

30. Boschi S, Lee JT, Beykan S, Slavik R, Wei L, Spick C, et al. Synthesis and preclinical evaluation of an AI(18)F radiofluorinated GLU-UREA-LYS(AHX)HBED-CC PSMA ligand. Eur J Nucl Med Mol Imaging. 2016;43(12):2122-30.

31. Giglio J, Zeni M, Savio E, Engler H. Synthesis of an Al(18)F radiofluorinated GLU-UREA-LYS(AHX)-HBED-CC PSMA ligand in an automated synthesis platform. EJNMMI Radiopharm Chem. 2018;3(1):4

32. Richarz R, Krapf P, Zarrad F, Urusova EA, Neumaier B, Zlatopolskiy BD. Neither azeotropic drying, nor base nor other additives: a minimalist approach to 18F-labeling. Org Biomol Chem. 2014;12(40):8094-9.

33. Eder $M$, Neels $O$, Müller $M$, Bauder-Wüst $U$, Remde $Y$, Schäfer $M$, et al. Novel preclinical and radiopharmaceutical aspects of [68Ga]Ga-PSMA-HBED-CC: a new pet tracer for imaging of prostate cancer. Pharmaceuticals (Basel). 2014;7(7):779-96.

34. Schäfer M, Bauder-Wüst U, Leotta K, Zoller F, Mier W, Haberkorn U, et al. A dimerized urea-based inhibitor of the prostate-specific membrane antigen for 68Ga-PET imaging of prostate cancer. EJNMMI Res. 2012;2(1):23.

35. Sanchez-Crespo A. Comparison of Gallium-68 and Fluorine-18 imaging characteristics in positron emission tomography. Appl Radiat Isot. 2013;76:55-62.

36. Dietlein M, Kobe C, Kuhnert G, Stockter S, Fischer T, Schomäcker K, et al. Comparison of [18F]DCFPyL and [68Ga]Ga-PSMA-HBED-CC for PSMA-PET imaging in patients with relapsed prostate cancer. Mol Imaging Biol. 2015;17(4):575-84.

37. Beheshti M, Rezaee A, Geinitz H, Loidl W, Pirich C, Langsteger W. Evaluation of prostate cancer bone metastases with $18 \mathrm{~F}-\mathrm{NaF}$ and $18 \mathrm{~F}-$ Fluorocholine PET/CT. J Nucl Med. 2016;57(Suppl 3):55S-60S.
38. Hao G, Kumar A, Dobin T, Oz OK, Hsieh JT, Sun X. A multivalent approach of imaging probe design to overcome an endogenous anion binding competition for noninvasive assessment of prostate specific membrane antigen. Mol Pharm. 2013;10(8):2975-85.

39. Jimenez-Andrade JM, Herrera MB, Ghilardi JR, Vardanyan M, Melemedjian OK, Mantyh PW. Vascularization of the dorsal root ganglia and peripheral nerve of the mouse: implications for chemical-induced peripheral sensory neuropathies. Mol Pain. 2008;4:10.

40. Bielenberg DR, Zetter BR. The contribution of angiogenesis to the process of metastasis. Cancer J. 2015;21(4):267-73.

\section{Publisher's Note}

Springer Nature remains neutral with regard to jurisdictional claims in published maps and institutional affiliations.
Ready to submit your research? Choose BMC and benefit from:

- fast, convenient online submission

- thorough peer review by experienced researchers in your field

- rapid publication on acceptance

- support for research data, including large and complex data types

- gold Open Access which fosters wider collaboration and increased citations

- maximum visibility for your research: over $100 \mathrm{M}$ website views per year

At $\mathrm{BMC}$, research is always in progress.

Learn more biomedcentral.com/submissions 